\title{
The Prevalence and Types of Advance Care Planning Use in Patients with Advanced Cancer: A Retrospective Single-Centre Perspective, Australia
}

\section{Arron S. Veltre}

The University of Newcastle

Andrew Broadbent

Gold Coast University Hospital

Jasotha Sanmugarajah

Gold Coast University Hospital

Amy Marshall

Fremantle Hospital

Mohammad Hamiduzzaman ( $\nabla$ Khoka.hamiduzzaman@newcastle.edu.au )

The University of Newcastle

\section{Research Article}

Keywords: Advance Care Planning, Advance Health Directive, Enduring Power of Attorney, Acute Resuscitation Plan, Palliative Chemotherapy, Futile Treatment

Posted Date: March 31st, 2021

DOl: https://doi.org/10.21203/rs.3.rs-372446/v1

License: (c) (1) This work is licensed under a Creative Commons Attribution 4.0 International License.

Read Full License 
Title: The Prevalence and Types of Advance Care Planning Use in Patients with Advanced Cancer: A Retrospective Single-Centre Perspective, Australia

\section{List of Authors}

Dr. Arron S. Veltre FRACGP FAChPM, Clinical Dean, Manning Education Centre, Department of Rural Health, College of Health Medicine \& Wellbeing, The University of Newcastle, Australia \& Department of Palliative Care, Manning Base Hospital, NSW, Australia. Email: arron.veltre@ newcastle.edu.au

A/Prof Andrew Broadbent MBChB MHM FAChPM FRACP, Director, Department of Supportive and Specialist Palliative Care, Gold Coast University Hospital, Queensland, Australia \& Bond University, Queensland, Australia. Email: Andrew.Broadbent@health.qld.gov.au

A/Prof Jasotha Sanmugarajah MBBS, M.D. FRACP, Director, Department of Oncology, Gold Coast University Hospital, Queensland, Australia \& Griffith School of Medicine, Queensland, Australia. Email: jasotha.sanmugarajah@health.qld.gov.au

Dr. Amy Marshall M.D., General Practice Registrar, Fremantle Hospital \& Health Service, Western Australia, Australia. Email: amymarshall744@gmail.com

Dr Mohammad Hamiduzzaman PhD Research Fellow, Department of Rural Health, College of Health Medicine \& Wellbeing, The University of Newcastle, Australia. Email: Khoka.hamiduzzaman@newcastle.edu.au,_ORCID ID - 0000-0001-6027-1564

Corresponding author: Dr Mohammad Hamiduzzaman, Research Fellow, Department of Rural Health, College of Health, Medicine \& Wellbeing, The University of Newcastle, Australia. Email: Khoka.hamiduzzaman@newcastle.edu.au

Running Head Advance Care Planning use in patients with advanced cancer 


\section{Key Points}

Question What is the prevalence and types of Advance Care Planning use in patients with advanced cancer in Gold Coast University Hospital, Australia?

Findings This retrospective audit of 320 patients found low Advance Care Planning invitation and utilisation rates, especially in the patients who received chemotherapy in their last 2-weeks of life. In the oncology setting, completion of Acute Resuscitation Plans and Advance Health Directives significantly differed between the control, $<2$-weeks, and 2-4 weeks groups, identifying the $<2$-weeks patient group as the lowest utiliser.

Meaning The low utilisation of Advance Care Planning in patients with advanced cancer decreases the scope of recognising their preferences at end-of-life care that indicates a need for an embedded framework along with education and training for the staff and patients. 


\begin{abstract}
Background: Advance Care Planning (ACP) has been reported to be of value in maintaining patients' autonomy and dignity; reducing patient and family anxiety; improving end-of-life care and reducing futile interventions. But in Australia participation rate in advance care directives is $14 \%$, and research is limited on ACP invitations and uptake among the patients with advanced cancer (PwAC). This study identifies the prevalence and types of documented ACP discussions in PwAC who died within two or four weeks of receiving chemotherapy.
\end{abstract}

Methods: A retrospective audit was conducted in Gold Coast University Hospital, Australia, and the records of 339 patients were examined and 320 patients were found eligible. Descriptive statistics were calculated in SPSS. The difference in ACP invitation and utilisation between three groups [control, <2-weeks, and -4 weeks] was measured by the Kruskal-Wallis test and Chi-square (or Fisher-Exact) test. Post-hoc follow-up pair-wise comparisons were performed. Adjusted prevalence ratios were estimated using two logistic regression models, and the significance of the coefficients was assessed using Wald test.

Results: Of the 320 PwAC [male: 55\%; median age: 65 years], 227 (71\%) received ACP invitation, and among the invited patients, 89\% used Acute Resuscitation Plan; 54\% used Enduring Power-of-Attorney; and 20\% completed Advance Health Directive. From 7.5\% [n=24] of the patients who received chemotherapy in their last 2-weeks of life, 42\% had not received an ACP invitation, 29\% didn't have Acute Resuscitation Plan and only 4\% completed Advance Health Directive. There were significant differences among the Control, <2weeks, and 2-4 weeks groups in completing Acute Resuscitation Plan $(p=0.003)$ and Advance Health Directives $(p=0.045)$. A significant difference was also observed between control and <2-weeks groups in number of days since Acute Resuscitation Plan used. Completing an Acute Resuscitation Plan was associated with a lower risk of dying within two-weeks of chemotherapy (OR=0.246; $p=0.008)$.

Conclusions: The low rates of ACP invitation and use in PwAC, especially who received chemotherapy in 2weeks of dying confirm a need of embedding and regular revisiting the ACP framework in cancer care and educating staff, patients, and their family caregivers to increase the uptake.

Keywords: Advance Care Planning, Advance Health Directive, Enduring Power of Attorney, Acute Resuscitation Plan, Palliative Chemotherapy, Futile Treatment. 


\section{Background}

Advance care planning (ACP) is widely reported to be of value in maintaining the patients' autonomy, reducing patient and family anxiety, improving end-of-life care and reducing futile or unwarranted intervention [1]. In Australia, terminology and its application vary across states and territories, but ACP generally involves Advance Care Plans; Advance Care Directives; Statement of Choices; Advance Health Directives; Enduring Powers of Guardianship and/or Attorney; and Acute Resuscitation Plan [2, 3]. It is recommended older adults begin ACP early, even when they are healthy, but individuals should particularly be encouraged to participate in the process when diagnosed with a life-limiting or chronic illness [4]. Evidence shows both invitations to ACP and completion of documentation are effective, for example, Houben et al. (2014) reported that increased documentation and discussions about care preference was correlated with patients' wishes being met [5]. Therefore, the ACP becomes integral to the care, communication and treatment plans for patients and their families and carers [4].

In 2011, the Australian government released a national framework on ACP that recommended they be part of hospital admissions/care protocols; accordingly, the country's states/territories circulated guidelines to increase the patients' ACP uptake [6]. Despite such efforts, national data suggests the use of ACP and frequency of end-of-life discussions have not kept pace, with 14\% of Australians having a completed Advance Care Directive [2]. A 2017 literature review identified the ACP prevalence of $12.7 \%$ in a retrospective USA study undertaken in 2015 assessed ACP practice with the largest international sample size of 24,291 [8]. Research is limited on ACP uptake in Australia, meaning there is a lack of evidence to assist hospitals and governments to understand the impact of ACP initiatives, especially for cancer patients [7].

Australian Institute of Health and Welfare (2014) identified cancer accounted for three out of every ten deaths in the country, and in 2011, cancer was responsible for $19 \%$ of the overall disease burden [9]. Compared to common non-cancer causes of death, cancer has a distinct trajectory of functional decline with a more predictable terminal period, which may be more conducive to ACP and palliative care [10]. Literature suggest cancer care continues to be highly intensive, driven in large part by local practice patterns as opposed to the patients' preferences $[11,12]$. Indeed, report published over a decade ago that described an environment of 
increasingly aggressive cancer care is mirrored in recent study showing persistent use of hospital-based services near death, despite evidence that aggressive end-of-life interventions may not be associated with better medical or quality of life outcomes [10].

Health status of cancer patients treated with chemotherapy often continues to deteriorate. There are benefits of chemotherapy in terms of symptom control, i.e., palliative chemotherapy [13], but ongoing use of chemotherapy must be balanced with the side effects and toxicity. Studies from North America point to a trend revealing increased use of chemotherapy in the last 2-weeks of life $[14,15,16,17,18]$. The benchmark for chemotherapy uses in the last 2-weeks of life was set by Earle et al. $(2004,2008)$, which states less than $10 \%$ of patients should be receiving chemotherapy prior to death $[14,15]$. The Adam et al.'s (2014) comparison table identified an Australian, single-centre study that looked at 747 patients who died across two cancer care departments in New South Wales and revealed $8 \%$ patients received palliative chemotherapy in the last 2weeks and $18 \%$ for 4 -weeks prior to death (where $\mathrm{n}=398$ ) $[19,20]$. Interestingly, the predictor of palliative chemotherapy continuation until the last 4 weeks of life in the study by Kao et al. (2009) was the treating oncologist, yet this was not a statistically significant effect for 2 -weeks prior to death [20]. It is, therefore, pertinent that all cancer patients receiving chemotherapy, especially those with advanced stages of disease, should have had in-depth discussions with health staff about their end-of-life care.

As noted earlier, little is known about the invitation and uptake of ACP in the patients with advanced cancer (PwAC). In 2014, a review of 113 studies on the effects of ACP, only 18\% (20 studies) reported on complex ACP interventions and only two of them included patients with cancer [1]. The studies were limited in their objectivity, as results were self-reported by next-of-kin after the patients had died. Currently, there exists disparity in the broader community in terms of preferences for end-of-life care including location of death, with $70 \%$ of the cohort stating a preference (in surveys) to have end-of-life care at home and yet $70 \%$ experience their end-of-life care in hospital [21]. It remains a challenge to determine if the PwAC wishes are being met, if they are not being documented in the first place, ultimately resulting in reduced levels of patient care and autonomy. We, therefore, aim to estimate the prevalence and types of ACP utilisations in PwAC who 
have received chemotherapy. Our study also examined the use of chemotherapy and ACP for the subgroups of patients who received chemotherapy up until their last 2-and 4-weeks of life.

\section{Methods}

\section{Study design}

This retrospective audit examined the ACP documentation contained in the records of 339 oncology patients who received chemotherapy for solid tumours and who died between January 1, 2016 and April 30, 2017.

\section{Settings and subjects}

The audit was conducted at Gold Coast University Hospital, Australia, which is a tertiary referral-centre servicing a population of 600,000 and only public oncology service in the region. The audit primarily focussed on oncology patients who were treated for solid tumours. A patient was defined in this study who was seen by oncology team and underwent at least one-cycle of chemotherapy/immunotherapy treatment. Patients with advanced solid tumours were included in this study. Generally, the PwAC would be present as an inpatient and subsequently receive a booking confirmation for chemotherapy treatment in oncology unit. The patients who met the oncology team and did not proceed to chemotherapy/immunotherapy intervention were excluded, resulted in 320 patients who met the inclusion criteria [Figure 1]. The median age of all patients was 65 years, with a range from 21 to 94 years and 55\% males.

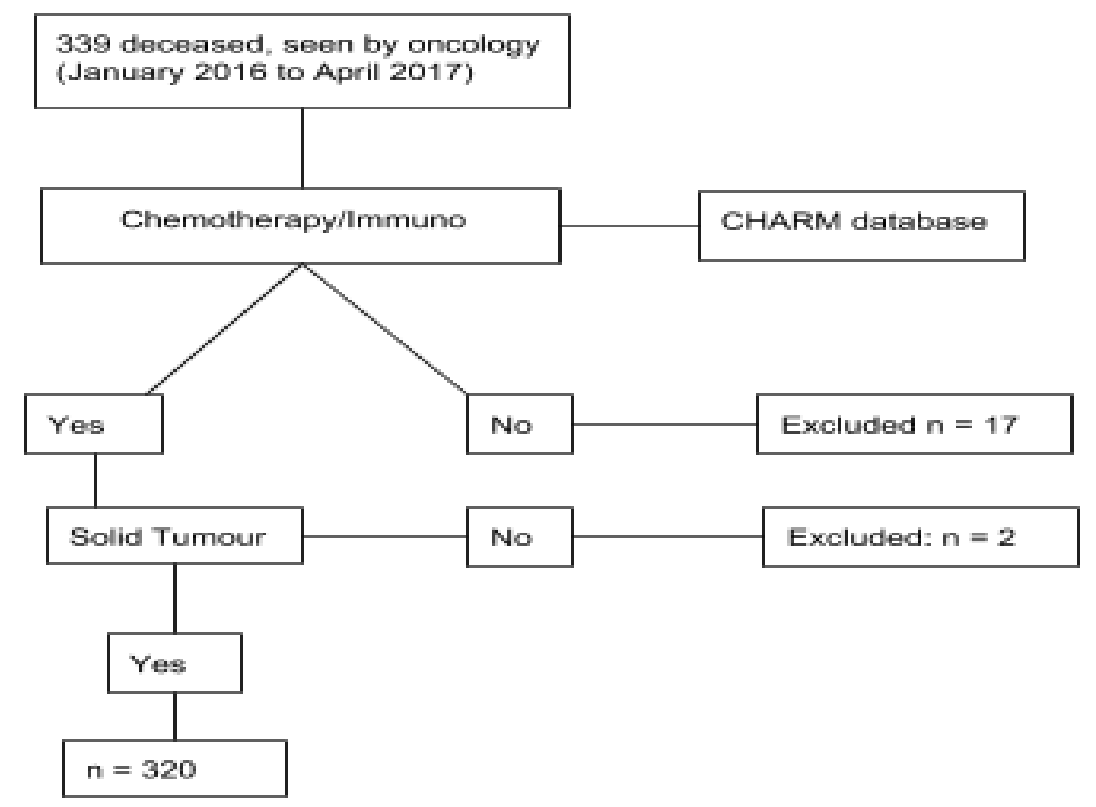

Figure 1. Method Flow Chart 


\section{Data collection}

Data was collected from hospital administration records; electronic medical records (EMR); and the chemotherapy pharmacy treatment database ('CHARM'). Specifically, the researchers retrieved data about how many PwAC had completed Advance Health Directives, an invitation to participate in any ACPs, a documented Advance Resuscitation Plan, a nominated default decision maker or Enduring Power-of-Attorney. Data was also collected for type of cancer, treating oncologist, date of last chemotherapy and place of death.

The spreadsheet was constructed in Excel with the first column pertaining to patient identification. Data extracted from the electronic medical record for entry into the spreadsheet included the following patient characteristics: gender, age, date of death, presence of a documented Advance Health Directive, of an Enduring Power-of-Attorney, an Acute Resuscitation Plan and an invitation to ACP. Place of death was also extracted from individual EMR. The database CHARM was used to obtain the variable of last chemotherapy treatment date and this was also recorded. The type of cancer and treating oncologist was obtained via EMR notes and cross-referenced with the CHARM database.

The ACP information was not always in the allocated section of EMR. In this case, a search of clinician notes (both inpatient and outpatient documentation) and social worker notes was undertaken. This process was repeated for the Enduring Powers of Guardianship and/or Attorney and invitation to ACP variables. Similarly, the Acute Resuscitation Plan was sometimes scanned into the EMR. If not, the aforementioned subsections of EMR were searched to confirm documentation of Acute Resuscitation Plan completion.

\section{Data Analysis}

Continuous variables were summarized using means and standard deviations. Categorical variables were summarized as counts and percentages. Percentages were calculated in SPSS after excluding the missing values. The percentage of the missing values did not exceed 5\% for any of the variables. The PwAC were grouped into three cohorts [control, <2-weeks, and 2-4 weeks] to understand whether ACP invitation and participation had occurred in the context of treatment futility. The Kruskal-Wallis test was therefore used to compare the distribution of continuous variables between the groups to test whether the distribution was 
significantly different. Chi-square (or Fisher-Exact) test was used to compare the categorical variables between the three groups. In both cases, post-hoc follow up pair-wise comparisons were performed if the initial test results were significant to compare each pair of groups. Bonferroni correction was used to adjust the p values.

Two binary logistic regression models were developed:

1. Model 1: Compare the 2-weeks cohort to the control cohort (rest of the cohort excluding the 2-4 weeks group).

2. Model 2: Compare the 2-4 weeks cohort to the control cohort (rest of the cohort excluding the 2-week group)

Before performing logistic regression, days since Acute Resuscitation Plan and days since ACP were log transformed. Odds ratio was calculated, and the significance of the coefficients was assessed using Wald test. Likelihood ratio test was performed to assess whether the constructed models (which includes the independent variables) were significantly better than the null model.

\section{Ethics}

Ethics approval for the audit was granted by Gold Coast University Hospital and Health District Human Research Ethics Committee [Project Number: HREC/17/QGC/200]. The PwAC were de-identified and their hospital identification numbers were used to ensure privacy. The de-identified data was stored in a spreadsheet format on a computer with password encryption and kept at the hospital for analysis and comparison.

\section{Results}

Table 1 illustrates the types of ACP invitations and their uptake by the PwAC. About $71 \%(n=227)$ of the total patients received ACP invitation. Of them, 20\% completed an Advance Health Directive; 89\% had an Acute Resuscitation Plan; and 54\% had an Enduring Power-of-Attorney. From 7.5\% of the PwAC who received chemotherapy in their last 2-weeks of life, 42\% had not received an ACP invitation, 29\% didn't have an Acute Resuscitation Plan and just 4\% had an Advance Health Directive.

Table 1 also shows the significant difference with respect to types of ACPs use between the three groups [Control VS <2-weeks VS 2-4 weeks]. The proportion of individuals who completed an Acute Resuscitation 
Plan was significantly different between the three groups $(p=0.003)$. Post-hoc comparisons showed that the proportion was higher in the control groups compared to the <2-weeks group only, but not the 2-4 weeks group. The proportion of PwAC who completed an Advance Health Directives was significantly different between the three groups $(p=0.045)$. Post-hoc analysis showed results similar to those noted with Acute Resuscitation Plan. Patients treated by one particular oncologist were significantly higher in the <2-weeks group compared to the control group, but not in the 2-4 weeks group. The proportion of males was higher in control group compared to the $<2$ weeks group and the 2-4 weeks group. The proportion of patients treated with immunotherapy was not significantly different between the three groups $(p=0.794)$. The location of death was not significantly different between the groups $(p=0.759)$. And the types of cancer was not significantly different between the groups.

Table 1. Descriptive statistics for categorical variables $(n=320)$

\begin{tabular}{|c|c|c|c|c|c|}
\hline & & $\begin{array}{l}<2 \text { Weeks } \\
(n=24)\end{array}$ & $\begin{array}{l}<2-4 \text { Weeks } \\
(n=27)\end{array}$ & $\begin{array}{l}\text { Control } \\
(n=269)\end{array}$ & $\mathbf{p}$ \\
\hline \multirow[t]{7}{*}{$\begin{array}{l}\text { Advance } \\
\text { planning }\end{array}$} & $\mathrm{AHD}(\%)$ & $1(4.2)^{\mathrm{a}}$ & $3(11.1)^{\mathrm{a}, \mathrm{b}}$ & $59(21.9)^{\mathrm{b}}$ & $0.045^{*}$ \\
\hline & EPOA $(\%)$ & $10(41.7)$ & $10(37.0)$ & $151(56.1)$ & 0.08 \\
\hline & $\mathrm{ACP}(\%)$ & $14(58.3)$ & $19(70.4)$ & $196(72.9)$ & 0.316 \\
\hline & $\operatorname{SOC}(\%)$ & $3(12.5)$ & $2(7.4)$ & $32(11.9)$ & 0.877 \\
\hline & $\operatorname{ARP}(\%)$ & $17(70.8)^{\mathrm{a}}$ & $22(81.5)^{\mathrm{a}, \mathrm{b}}$ & $246(91.4)^{b}$ & $0.003 *$ \\
\hline & Gender (Male) (\%) & $9(37.5)$ & $10(37.0)$ & $156(58.0)$ & 0.024 \\
\hline & Immunotherapy (\%) & $5(20.8)$ & $5(18.5)$ & $46(17.1)$ & 0.794 \\
\hline Doctor $(\%)$ & Doctor 1 & $8(33.3)^{\mathrm{a}}$ & $4(14.8)^{\mathrm{a}, \mathrm{b}}$ & $32(11.9)^{\mathrm{b}}$ & $0.0138 *$ \\
\hline \multirow[t]{4}{*}{ Death location (\%) } & Hospital (inpatient) & $19(82.6)$ & $19(76)$ & $199(76.2)$ & \\
\hline & Home & $4(17.4)$ & $6(24.0)$ & $42(16.1)$ & 0.759 \\
\hline & Hospice ( 8 bed facility) & $0(0.0)$ & $0(0.0)$ & $16(6.1)$ & \\
\hline & RACF (Nursing Home) & $0(0.0)$ & $0(0.0)$ & $4(1.5)$ & \\
\hline \multirow[t]{12}{*}{ Cancer $(\%)$} & Breast & $3(12.5)$ & $3(11.1)$ & $18(6.7)$ & 0.379 \\
\hline & CNS & $0(0.0)$ & $0(0.0)$ & $11(4.1)$ & 0.54 \\
\hline & Genito-urinary & $2(8.3)$ & $3(11.1)$ & $31(11.6)$ & 1 \\
\hline & GI & $6(25.0)$ & $7(25.9)$ & $92(34.5)$ & 0.527 \\
\hline & Gynae & $3(12.5)$ & $1(3.7)$ & $9(3.4)$ & 0.093 \\
\hline & Head \& neck & $0(0.0)$ & $1(3.7)$ & $10(3.7)$ & 1 \\
\hline & Lung & $8(33.3)$ & $6(22.2)$ & $51(19.1)$ & 0.241 \\
\hline & Melanoma & $0(0.0)$ & $1(3.7)$ & $7(2.6)$ & 0.757 \\
\hline & NEC/NET & $0(0.0)$ & $0(0.0)$ & $5(1.9)$ & 1 \\
\hline & Other & $0(0.0)$ & $0(0.0)$ & $10(3.7)$ & 0.826 \\
\hline & small cell lung & $2(8.3)$ & $3(11.1)$ & $19(7.1)$ & 0.61 \\
\hline & Unknown primary & $0(0.0)$ & $2(7.4)$ & $4(1.5)$ & 0.149 \\
\hline
\end{tabular}

Different superscripts indicate that the groups are significantly different from each other

$\mathrm{ACP}=$ Advance Care Plan; AHD = Advance Health Directive; EPOA = Enduring Power of Attorney; ARP = Acute Resuscitation Plan; $\mathrm{SOC}=$ Statement of choices invitation

RACF $=$ Residential Aged Care Facility

Hospice $=8$ bed facility not attached to the hospital (not a palliative care unit) 
Table 2 shows that there was a significant difference in the number of days since Acute Resuscitation Plan between control and $<2$ weeks group, meaning that the Acute Resuscitation Plan often filled out by the oncology team as the patients' condition deteriorates and they approach end-of-life. There was also a significant difference between the <2-weeks and the 2-4 weeks group. However, there was no significant difference in the days since Acute Resuscitation Plan between the control group and the 2-4 weeks group. Results show that there were no significant differences between the three groups with respect to age or days since ACP.

Table 2. Descriptive statistics for continuous variables $(\mathbf{n}=320)$

\begin{tabular}{lllll}
\hline & Control $(\mathbf{n = 2 6 9})$ & $<\mathbf{2}$ Weeks $(\mathbf{n = 2 4})$ & $\mathbf{2 - 4}$ Weeks $(\mathbf{n}=\mathbf{2 7})$ & $\mathbf{p}$ \\
\hline Age & $67.00[58.00,73.00]$ & $68.00[55.75,74.00]$ & $62.00[55.50,73.00]$ & 0.661 \\
Days since ARP & $17.50[6.00,54.75]^{\mathrm{a}}$ & $3.00[2.00,8.00]^{\mathrm{b}}$ & $10.00[7.00,13.00]^{\mathrm{a}}$ & $<0.001^{*}$ \\
Days since ACP & $41.50[15.25,101.75]$ & $66.50[17.00,115.75]$ & $57.00[30.00,94.00]$ & 0.494 \\
\hline Different superscripts indicate that the groups are significantly different from each other &
\end{tabular}

Table 3a. Predictors of death within two weeks of chemotherapy $\left(\mathrm{R}^{2}=16.7 \%\right)$ [<2-week group vs cohort]

\begin{tabular}{l|l|l|l|l|l}
\hline Variable & Odds ratio & Lower 95\% CI & Upper 95\% CI & Wald stat & P value \\
\hline Gender (Male) & 0.41 & 0.156 & 0.99 & -1.94 & 0.053 \\
\hline AHD & 0.182 & 0.01 & 0.923 & -1.63 & 0.1 \\
\hline ARP & 0.246 & 0.088 & 0.73 & -2.64 & $0.008^{*}$ \\
\hline Oncologist (1) & 3.45 & 1.25 & 8.97 & 2.49 & $0.0128^{*}$ \\
\hline \multicolumn{1}{l}{ Table 3b. Predictors of death within 2-4 weeks of chemotherapy $\left(\mathrm{R}^{2}=5.8 \%\right)[2-4$ weeks group vs. cohort] } \\
\hline Variable & Odds ratio & Lower 95\% CI & Upper 95\% CI & Wald stat & P value \\
\hline Gender (Male) & 0.44 & 0.187 & 0.988 & -1.95 & 0.051 \\
\hline AHD & 0.493 & 0.113 & 1.51 & -1.11 & 0.266 \\
\hline ARP & 0.473 & 0.169 & 1.55 & -1.35 & 0.178 \\
\hline Oncologist (1) & 1.173 & 0.32 & 3.4 & 0.27 & 0.787 \\
\hline
\end{tabular}

Table $3 \mathrm{a}$ and $3 \mathrm{~b}$ present the logistic regression analysis results. Males were 59\% less likely to die within 2weeks of chemotherapy compared to the females. Completing an Advance Health Directives was not significantly associated with dying within 2-weeks of chemotherapy $(p=0.1)$. But completing an Acute Resuscitation Plan was associated with a lower risk of dying within 2-weeks of chemotherapy (OR=0.246; $p=0.008$ ), the odds of dying within 2-weeks of chemotherapy among the PwAC who completed an Acute Resuscitation Plan was $75.4 \%$ lower compared to those who did not. There was a significant difference in 
treatment up to 2-weeks prior to death for one particular oncologist. Table $3 \mathrm{~b}$ reports that males were $56 \%$ less likely to die within 2-4 weeks of chemotherapy compared to their counterpart. None of the remaining variables was significantly associated with dying within 2-4 weeks of chemotherapy.

\section{Discussion}

The study findings confirmed that the invitation and utilisation of ACP in the PwAC, especially in the patients who received chemotherapy in their last 2-weeks of life have remained consistently low across Australia despite high levels of relevance and applicability. Various studies revealed the importance of ACP documentation in maintaining patient preferences for care [1,5]. Brinkman-Stoppelenburg et al. (2014) outlined the evidence for ACP and its positive impact on patient outcomes [1]. However, not all ACP documents are equivalent and therefore may be less likely to ensure patient outcomes. The Acute Resuscitation Plan was the most completed documented in our study yet contains the least legal power to ensure the PwAC outcomes. The Acute Resuscitation Plan completion is not dependent on the PwAC signatures, but rather involves verification through a hospital doctor only. Rietjens et al. (2016) highlighted the importance of patient engagement in decision making around end-of-life care preferences [23]. A document with greater PwAC involvement may increase the likelihood of achieving their preferences. In terms of the patient preference, the Advance Health Directives requires the greatest patient involvement, has a greater level of legal power (depending on state legislation), yet was the most under-represented document in our study.

As a suite of documents, the ACP process has two main components: i. surrogate decision maker; and ii. documents related to patient preferences. In our study 53\% of PwAC had a formally allocated a surrogate decision maker via completion of an Enduring Powers of Guardianship and/or Attorney. Despite advanced oncological illness, approximately half the PwAC in our study did not complete an Enduring Powers of Guardianship and/or Attorney and for those who did it was completed nine weeks prior to death (median time frame). In oncology setting, for the PwAC who are receiving chemotherapy/immunotherapy, there exists a distinct timeframe advantage and occasionally predictable functional decline associated with advanced disease. Such death trajectories allow more time for completion and regular revisitation of documents which should align with treatment goals. It could be assumed that many PwAC who did not formally document a decision 
maker may believe that family members or carers were adequately informed of their wishes. Shalowitz et al. (2006) revealed the PwAC surrogate decision makers incorrectly predicted patient preferences in one third of cases [37].

In terms of decision making, it is of note that median time frames for Acute Resuscitation Plan completion in our study were the shortest for the PwAC who died within 2-weeks of receiving chemotherapy. This result was significant in our study but also speaks to the reality of advanced cancer. Hebert and Selby (2014) suggested family members and patients should be provided with an explanation of non-reversible aspects of an illness to help guide resuscitation plans [38]. In the case of progressive/advanced cancer, the ARP is more representative of a change in the goals of care or treatment goals, and discussions are often centred around an upper limit of care. Revisions or alterations in resuscitation plans are therefore more likely to occur when a patient is clearly declining and approaching end-of-life.

Our study revealed that the male PwAC were approximately 59\% and 56\% less likely to die within 2-weeks or 4-weeks of receiving chemotherapy respectively compared with females. While the results were significant, it may also be explained by the types of solid tumours affecting both genders in our study. The literature points to a greater percentage of female-specific cancers that are treated as chronic diseases or maintenance therapies [39]. A study by Nevadunsky et al. (2013) concluded that women with gynaecological malignancies undergo aggressive treatments at end-of-life without any evidence of improved quality of life or longevity [40]. Despite the current study partly supporting the findings of Nevadunsky et al. (2013), there were no statistically significant differences between ACP documentation related to gender.

Barriers to participation in ACP have been investigated by several studies [24, 25, 26]. Michael et al. (2013) suggested a lack of disease specific ACP discussions and outlined the importance of ACP intervention as several discussions throughout the disease trajectory [24]. Optimal time frames for ACP discussions for oncology patients undergoing chemotherapy intervention remain unclear. In particular, studies should look at the time between the initial development of ACP and the subsequent revisions of the plan as suggested for all patients on the end-of-life spectrum as indicated in the consensus guidelines for quality end-of-life care [21]. 
The quality and content of end-of-life discussions, along with early palliative care involvement has been identified as a significant variable in the development and implementation of ACPs and may require guideline development to ensure a consistently effective approach [24, 26, 27].

This study was limited by a lack of documented hospital admissions in the last-weeks prior to death and the intervention received during this time. Limited data collected on revisions to ACP, i.e., in some cases the Acute Resuscitation Plan or Advance Health Directives were revised several times and the data did not capture this. Statement of choices documentation was not included in the ACP invitations in 2016. However, the study generates evidence for a specific cohort examined and the relevance of ACP implementation in the context of imminent death. Also, it provides pertinent and scarcely available data on the utilisation of ACP in oncology patients that would benefit the practitioners in engaging the patients and their families in ACP.

\section{Impact statement}

$\notin \quad$ An indication as to which forms of ACP are utilised by Oncology patients with solid tumors;

$\notin$ Results showing low rate of invitations to participate in ACP and completion of Advance Health Directives in patients who died after receiving chemotherapy treatment;

$\notin \quad$ Significantly low ACP rate for subgroup of patients receiving futile treatment (within 2-weeks of death); and

$\notin$ The data from this study may guide future research and population-based intervention in attempting to improve the uptake of ACP.

\section{Conclusions}

This study revealed that despite government initiatives, ACP prevalence rates are not improving among the PwAC. Of concern are the decreased rates of completion for the PwAC receiving potentially futile treatment in their last weeks of life. Our evaluation of ACP rates in a population of advanced oncology revealed the common form of ACP completion was the Acute Resuscitation Plans followed by Enduring Powers of Guardianship and/or Attorney and then Advance Health Directives. Significantly, Advance Health Directives completion rates in this setting were almost identical to Australian population rates, despite advanced disease. 
The study highlights the need for a range of strategies to improve ACP invitation and completion rates: first, embedding the ACP framework for all patients aged 65 years and over within hospitals; second, ACP education, training and mentoring for staff; third, engaging social workers in health literacy interventions to educate patients and their family caregivers about ACP uptake; and finally, revising the ACP documentation in regular intervals with disease progression. Further research should focus on barriers to ACP completion in the oncology setting, which may have broader application to the PwAC and ensure patient preferences are aligned with care received.

\section{Declarations}

Ethics approval: This study is approved by Gold Coast University Hospital and Health District Human Research Ethics Committee [Project Number: HREC/17/QGC/200].

Consent to participate: Not Applicable

Consent for publication: All authors read and approve the submission.

Availability of data and materials: The datasets used and/or analyzed during the current study are available from the corresponding author on reasonable request.

Competing interests: The authors declared no conflicts of interest.

Funding: Not funded.

Authors' contributions AV made substantial contributions to conception and design, acquisition of data, analysis and interpretation of data. Responsible for drafting the manuscript and revising it critically for important intellectual content. AB, GS, AM and MH made substantial contributions to shaping the conception and design. Involved in drafting the manuscript and revising it critically for important intellectual content. AV and $\mathrm{MH}$ involved in reviewing the manuscript, contribute to developing methodological and oncological frames, and revising it critically for important intellectual content. All authors read and approved the final manuscript.

Acknowledgements: Ahmed Khan - Statistical analysis. 


\section{References}

[1] Brinkman-Stoppelenburg A, Rietjens J, van der Heide A. The effects of advance care planning on end-oflife care: A systematic review. Palliative Medicine. 2014;28(8):1000-1025.

[2] White B, Tilse C, Wilson J, et al. Prevalence and predictors of advance directives in Australia. Intern Med J 2014;44:975-80.

[3] Powers of Attorney Act, 1998, QLD, 2018.

[4] Fried T, Bullock K, Iannone L, O'Leary J. Understanding Advance Care Planning as a Process of Health Behavior Change. Journal of the American Geriatrics Society. 2009;57(9):1547-1555.

[5] Houben C, Spruit M, Groenen M, Wouters E, Janssen D. Efficacy of Advance Care Planning: A Systematic Review and Meta-Analysis. Journal of the American Medical Directors Association. 2014;15(7):477-489.

[6] A National Framework for Advance Care Directives, 2011 Available from: www.ahmac.gov.au

[7] Johnson S, Kerridge I, Butow P, Tattersall M. Advance Care Planning: is quality end of life care really that simple? Internal Medicine Journal. 2017;47(4):390-394.

[8] Johnson S, Butow P, Kerridge I, Tattersall M. Advance care planning for cancer patients: a systematic review of perceptions and experiences of patients, families, and healthcare providers. Psycho-Oncology. 2016;25(4):362-386.

[9] Cancer in Australia: an overview 2014, Formats - Australian Institute of Health and Welfare [Internet]. Australian Institute of Health and Welfare. 2018 [cited 21 May 2018]. Available from: https://www.aihw.gov.au/reports/cancer/cancer-in-australia-an-overview-2014/formats

[10] Narang A, Wright A, Nicholas L. Trends in Advance Care Planning in Patients with Cancer. JAMA Oncology. 2015;1(5):601.

[11] Matsuyama R, Reddy S, Smith TJ: Why do patients choose chemotherapy near the end of life? A review of the perspective of those facing death from cancer. J Clin Oncol, 2006;24: 3490-3496.

[12] Morden NE, Chang C, Jacobson JO, et al. End-of-life care for Medicare beneficiaries with cancer is highly intensive overall and varies widely. Health Aff (Millwood). 2012; 31(4):786-96.

[13] Roeland E, LeBlanc T. Palliative chemotherapy: oxymoron or misunderstanding?. BMC Palliative Care. 2016;15(1). 
14] Earle CC, Landrum MB, Souza JM, Neville BA, Weeks JC, Ayanian JZ: Aggressiveness of cancer care near the end of life: is it a quality-of-care issue? J Clin Oncol, 2008; 26:3860-3866.

[15] Earle CC, Neville BA, Landrum MB, et al.: Trends in the aggressiveness of cancer care near the end of life. J Clin Oncol 2004;22:315-321.

[16] Ho TH, Barbera L, Saskin R, Lu H, Neville BA, Earle CC: Trends in the aggressiveness of end-of-life cancer care in the universal health care system of Ontario, Canada. J Clin Oncol 2011, 29(12):1587-1591.

[17] Rochigneux P, Raoul J, Beaussant Y, Aubry R, Goldwasser F, Tournigand C et al. Use of chemotherapy near the end of life: what factors matter? Annals of Oncology. 2016;:mdw654.

[18] Zdenkowski N, Cavenagh J, Ku Y, Bisquera A, Bonaventura A. Administration of chemotherapy with palliative intent in the last 30 days of life: the balance between palliation and chemotherapy. Internal Medicine Journal. 2013;43(11):1191-1198.

[19] Adam H, Hug S, Bosshard G. Chemotherapy near the end of life: a retrospective single-centre analysis of patients' charts. BMC Palliative Care. 2014;13(1).

[20] Kao S, Shafiq J, Vardy J, Adams D. Use of chemotherapy at end of life in oncology patients. Annals of Oncology. 2009;20(9):1555-1559.

[21] Australian Commission on Safety and Quality in Health Care. National Consensus Statement: essential elements for safe and high-quality end-of-life care. Sydney: ACSQHC, 2015

[22] Foreman L, Hunt R, Luke C, Roder D. Factors predictive of preferred place of death in the general population of South Australia. Palliative Medicine. 2006;20(4):447-453.

[23] Rietjens J, Korfage I, van der Heide A. Advance care planning: Not a panacea. Palliative Medicine. 2016;30(5):421-422.

[24] Michael N, O'Callaghan C, Clayton J, Pollard A, Stepanov N, Spruyt O, Michael M, Ball D. Understanding how cancer patients actualise, relinquish, and reject advance care planning: implications for practice. Support Care Cancer. 2013 Aug;21(8):2195-205.

[25] Detering KM, Hancock AD, Reade MC, Silvester W. The impact of advance care planning on end-of-life care in elderly patients: randomised controlled trial. BMJ 2010; 340: c1345. 
[26] McDonald J, du Manoir JM, Kevork N, Le LW, Zimmermann C. Advance directives in patients with advanced cancer receiving active treatment: attitudes, prevalence, and barriers. Support Care Cancer. 2017 Feb;25(2):523-531.

[27] Teno J, Casey V, Welch L, Edgman-Levitan S. Patient-Focused, Family-Centered End-of-Life Medical Care. Journal of Pain and Symptom Management. 2001;22(3):738-751.

[28] Emanuel EJ, Young-Xu Y, Levinsky NG, Gazelle G, Saynina O, Ash AS: Chemotherapy use among Medicare beneficiaries at the end of life. Ann Intern Med, 2003;138: 636-643.

[29] American Society of Clinical Oncology: Outcomes of cancer treatment for technology assessment and cancer treatment guidelines. J Clin Oncol. 1996, 14: 671-679.

[30] Martoni AA, Tanneberger S, Mutri V: Cancer chemotherapy near the end of life: the time has come to set guidelines for its appropriate use. Tumori 2007, 93(5):417-422.

[31] Maltoni M, Caraceni A, Brunelli C, Broeckaert B, Christakis N, Eychmueller S, Glare P, Nabal M, Viganò A, Larkin P, De Conno F, Hanks G, Kaasa S: Prognostic factors in advanced cancer patients: evidence-based clinical recommendations - a study by the Steering Committee of the European Asso- ciation for Palliative Care. J Clin Oncol, 2005; 23: 6240-6248.

[32] Andreis F, Rizzi A, Rota L, Meriggi F, Mazzocchi M, Zaniboni A: Chemotherapy use at the end of life. A retrospective single centre experience analysis. Tumori 2011, 97(1):30-34.

[33] Sezgin Goksu et al.: Use of chemotherapy at the end of life in Turkey. BMC Palliative Care 2014 13:5

[34] ABS 2016. Deaths, Australia, 2015. ABS cat. no. 3302.0. Canberra: ABS.

[35] Department of Health and Ageing (DoHA). The National Palliative Care Strategy - Supporting Australians to Live Well at the End of Life. Canberra: DoHA; 2010.

[36] Lee H, Chun K, Moon D, yeon H, Lee S, Lee S. Trends in receiving chemotherapy for advanced cancer patients at the end of life. BMC Palliative Care. 2015;14(1).

[37] Shalowitz DI, Garrett-Mayer E, Wendler D. The Accuracy of Surrogate Decision Makers: A Systematic Review. Arch Intern Med. 2006;166(5):493-497. doi:10.1001/archinte.166.5.493

[38] Hébert PC, Selby D. Should a reversible, but lethal, incident not be treated when a patient has a do-notresuscitate order? CMAJ. 2014 Apr 15;186(7):528-30. 
[39] Earle CC, Landrum MB, Souza JM, Neville BA, Weeks JC, Ayanian JZ. Aggressiveness of cancer care near the end of life: is it a quality-of-care issue? Journal of clinical oncology. 2008 Aug 10;26(23):3860.

[40] Nevadunsky NS, Spoozak L, Gordon S, Rivera E, Harris K, Goldberg GL. End-of-life care of women with gynecologic malignancies: a pilot study. International Journal of Gynecologic Cancer. 2013 Mar 1;23(3). 
Figures

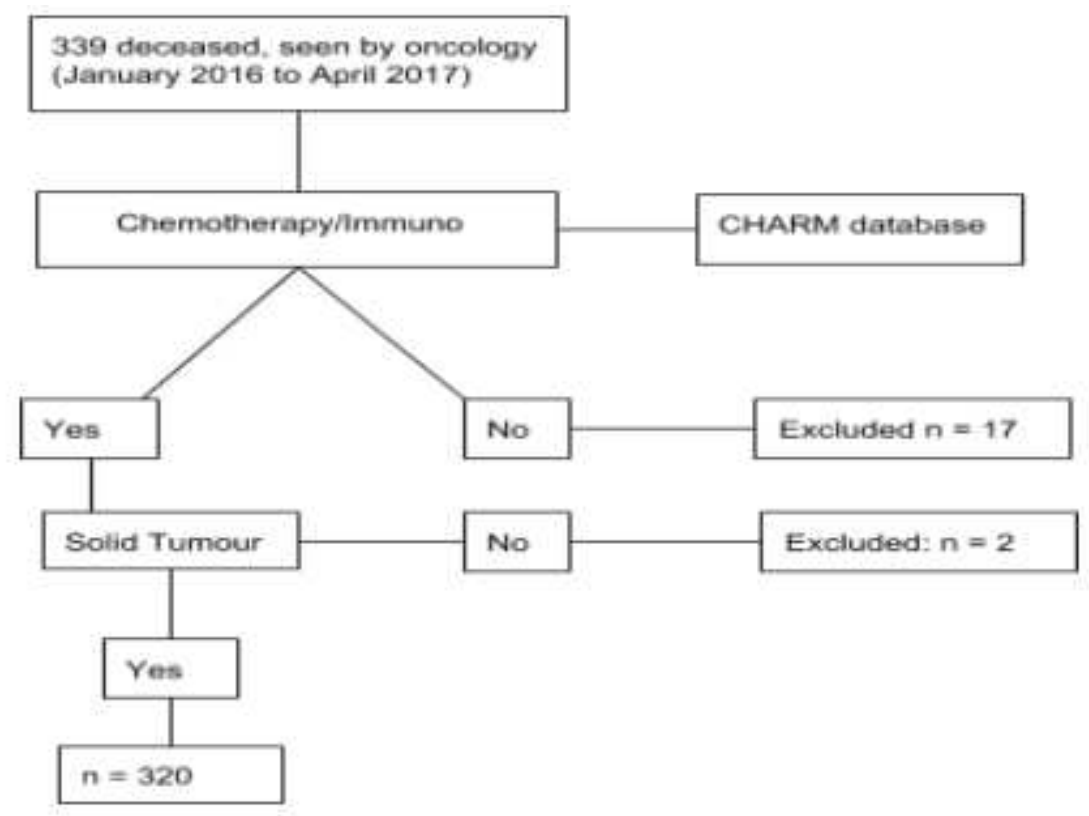

Figure 1

Method Flow Chart 